\title{
O gênero Senna Mill. (Leguminosae, Caesalpinioideae, Cassieae) no Parque Estadual da Serra Dourada, GO, Brasil
}

\author{
Murilo Melo Dantas ${ }^{1,2}$ e Marcos José da Silva ${ }^{1}$
}

Recebido: 5.10.2012; aceito: 31.01.2013

\begin{abstract}
The genus Senna Mill. (Leguminosae, Caesalpinioideae, Cassieae) in Parque Estadual da Serra Dourada, Goiás State, Brazil). A taxonomic study of the genus Senna in Parque Estadual da Serra Dourada, Goiás State, is presented as a part of the Project Diversity of Leguminosae of the Cerrado s.l. from Central Brazil. Ten taxa were recognized: Senna alata, S. corifolia var. caesia, S. georgica, S. multijuga subsp. multijuga, S. obtusifolia, S. occidentalis, S. pendula var. glabrata, S. pilifera, S. rugosa, and S. silvestris subsp. bifaria. Descriptions, identification key, illustrations, geographical distribution, and taxonomic comments of the taxa are provided.
\end{abstract}

Key words: Diversity, Fabaceae, Flora of the Cerrado, Taxonomy

RESUMO - (O gênero Senna Mill. (Leguminosae, Caesalpinioideae, Cassieae) no Parque Estadual da Serra Dourada, GO, Brasil). É apresentado o estudo taxonômico do gênero Senna para o Parque Estadual da Serra Dourada, GO, como parte do projeto Diversidade de Leguminosae do Cerrado do Brasil Central. Foram reconhecidos 10 táxons: Senna alata, S. corifolia var. caesia, S. georgica, S. multijuga subsp. multijuga, S. obtusifolia, S. occidentalis, S. pendula var. glabrata, S. pilifera, S. rugosa e S. silvestris subsp. bifaria. São apresentadas descrições, chave de identificação, ilustrações, distribuição geográfica e comentários taxonômicos dos táxons.

Palavras-chave: Diversidade, Fabaceae, Flora do Cerrado, Taxonomia

\section{Introdução}

Senna Mill. é o segundo maior gênero da tribo Cassieae subtribo Cassiinae com aproximadamente 300 espécies de distribuição pantropical. Nas Américas está representado por cerca de 200 espécies (Irwin \& Barneby 1982, Lewis 2005), 80 das quais registradas para o Brasil (Souza \& Bortoluzzi 2012). $\mathrm{O}$ gênero pode ser diagnosticado pelas flores amarelas, usualmente assimétricas, enantiostílicas, sem bractéolas no pedicelo, com androceu heteromórfico e anteras basifixas, bem como folhas comumente com nectários entre os pares de folíolos e frutos predominantemente indeiscentes (Irwin \& Barneby 1982).

Senna possui taxonomia relativamente estudada, sendo o trabalho de Irwin \& Barneby (1982) o mais abrangente para o gênero por reconhecer 260 espécies agrupadas em seis seções e 35 séries. No entanto, a maioria das seções e séries reconhecidas para Senna não é monofilética conforme Marazzi et al. (2006).

Após o estudo de Irwin \& Barneby (1982), contribuições à taxonomia das espécies brasileiras de Senna são escassas e o gênero teve sua taxonomia tratada apenas para a flora do Estado da Bahia (Lewis 1987), de Santa Catarina (Bortoluzzi 2004), do Rio Grande do Sul (Rodrigues et al. 2005) e de Pernambuco (Lima 1999). Além desses estudos, referências taxonômicas, biogeográficas e ecológicas sobre espécies de Senna são encontradas nos estudos florísticos pontuais de Fernandes (1962), Angely (1965), Lewis \& Owen (1989), Alves \& Sartori (2009), Queiroz (2009), Silva \& Tozzi (2010), entre outros.

Devido ao pouco conhecimento sobre a diversidade do gênero Senna, especialmente no bioma cerrado, objetivou-se realizar o tratamento taxonômico para as espécies desse gênero presentes no Parque Estadual Serra Dourada (PESD), GO, Brasil, visando contribuir

1. Universidade Federal de Goiás, Instituto de Ciências Biológicas, Departamento de Biologia Geral, Campus Samambaia II, Caixa Postal 131, 74001-970 Goiânia, GO, Brasil

2. Autor para correspondência: murylomello@hotmail.com 
para o conhecimento da diversidade florística das Leguminosae no bioma Cerrado, especialmente do Estado de Goiás.

\section{Material e métodos}

O Parque Estadual da Serra Dourada $\left(16^{\circ} 00^{\prime}-\right.$ $16^{\circ} 04^{\prime} \mathrm{S}$ e $50^{\circ} 30^{\prime} \mathrm{W}$ ) compreende a Serra Dourada e abrange os municípios de Buriti de Goiás e Mossâmedes possuindo uma área de 30.000 hectares composto por diferentes fitofisionomias (floresta estacional semidecidual, mata de galeria, cerrado s.s e rupestre, campos sujos e limpos) e tipos de solos (latossolos, cambissolos, neossolos, incluindo afloramentos rochosos) em altitudes entre 800$1.080 \mathrm{~m}$ (Rizzo 1970). Possui clima Aw com chuvas de outubro a abril e a temperatura média anual de 23,6 ${ }^{\circ} \mathrm{C}$ (Köppen 1948, Cochrane et al. 1985) e flora diversificada, incluindo espécies endêmicas, e pouco conhecida.

As coletas foram realizadas entre outubro de 2010 a maio de 2012 conforme os procedimentos metodológicos de Mori et al. (1989). O material coletado foi incorporado no acervo do Herbário UFG.

A identificação dos táxons foi feita por meio de literatura especializada (Irwin \& Barneby 1982) e por comparações com coleções dos herbários (UB, IBGE, CEN, UFG); enquanto que as descrições foram baseadas na análise morfológica dos espécimes coletados e nas informações contidas nos rótulos das exsicatas. Nas descrições dos táxons foram adotadas as terminologias encontradas em Irwin \& Barneby (1982). As ilustrações foram feitas com auxílio de estereomiscrocópio Zeiss, com câmara clara acoplada. O tratamento taxonômico foi elaborado no Laboratório de Morfologia e Taxonomia Vegetal da Universidade Federal de Goiás.

\section{Resultados e Discussão}

Senna Mill., Gard. Dict. Abr. ed. 4, v. 3. 1754.

Subarbustos, arbustos, ou árvores. Ramos eretos ou escandentes. Estípulas, tardiamente caducas a persistentes, com base nectarífera ou não. Folhas paripinadas, 4-multifolioladas, folíolos opostos, membranáceos a coriáceos. Nectário foliar, quando presente, na base do pecíolo ou entre os pares de folíolos, séssil ou estipitado, cônico, obcônico ou cilíndrico. Racemos ou panículas com eixos secundários corimbiformes ou não, axilares ou terminais; brácteas presentes, caducas ou persistentes; bractéolas ausentes. Flores 5-meras, enantiostílicas, zigomorfas ou assimétricas, pétalas heteromórficas, duas antero-laterais, duas postero-laterais e uma posterior, usualmente côncavas e cuculadas no ápice; sépalas livres, homomórficas ou heteromórficas, côncavas; estames 6-7, heteromórficos, sendo 4 medianos, eretos, subsésseis, 2-3 abaxiais maiores, 2 laterais, geralmente curvos e com filetes geralmente duas vezes maior que o comprimento das anteras, e um central menor ou estéril geralmente ereto com filete menor que a antera, além de 3-4 estaminódios adaxiais, todos com anteras poricidas pelo ápice; ovário séssil ou estipitado, geralmente indumentado, voltado para um dos lados da flor, raro central, estilete curvo. Frutos indeiscentes ou tardiamente deiscentes, cilíndricos, quadrangulares ou planos, glabros ou indumentados, alados ou não. Sementes obovoides, oblongas, rômbicas ou raramente elipsoides, castanho claras a escuras ou oliváceas, com linhas fraturais, organizadas em uma ou duas séries.

No Parque Estadual da Serra Dourada (PESD) Senna está representado por dez táxons, os quais podem ser reconhecidos pela chave abaixo:

Chave para os táxons de Senna ocorrentes no Parque Estadual da Serra Dourada

1. Folhas sem nectários

2. Folhas com 9-11 pares de folíolos; racemos congestos; frutos 2 alados 1. S. alata

2. Folhas com 4-8 pares de folíolos; panículas laxas; frutos não alados ... 10. S. silvestris subsp. bifaria

1. Folhas com nectários

3. Nectários entre todos os pares de folíolos

4. Folhas com 3-5 pares de folíolos; estípulas reniformes 2. S. corifolia var. caesia

4. Folhas com 2 pares de folíolos; estípulas linear-lanceoladas

5. Caule e ramos hirsutos; estípulas persistentes; frutos compressos 8. S. pilifera

5. Caule e ramos tomentosos; estípulas tardiamente caducas; frutos cilíndricos 9. S. rugosa

3. Nectários somente em alguns pares de folíolos ou na base do pecíolo 6. Nectário na base do pecíolo 6. S. occidentalis 
6. Nectários entre alguns pares de folíolos

7. Árvores ou arvoretas

8. Folhas com 18-24 pares de folíolos; folíolos oblongos com ápice obtuso

4. S. multijuga subsp. multijuga

8. Folhas com 2 pares de folíolos; folíolos oval-elípticos com ápice acuminado 3. S. georgica

7. Subarbustos a arbustos

9. Folhas com 2-3 pares de folíolos; flores em fascículos 5. S. obtusifolia

9. Folhas com 4-5 pares de folíolos; flores em racemos 7. S. pendula var. glabrata

1. Senna alata (L.) Roxb., F1. Ind. 2: 349. $1832 \equiv$ Cassia alata L., Sp. Pl. 1: 378. 1753. Figura 1a-e

Arbustos a arvoretas 1,2-3 m alt.; ramos glabros a pubérulos. Estípulas 1,4-1,6×0,7-1,1 cm, triangulares, persistentes, assimétricas, base provavelmente nectarífera. Folhas $30-48,5 \mathrm{~cm}$ compr., pecíolo 2-3,5 cm compr.; nectário extrafloral ausente; raque 28-45 cm compr., alada; segmentos interfoliolares 1,7-5 cm compr., folíolos 9-11 pares, 5-16,5 × 2-9 cm, oblongos, oblongo-obovais ou oblongo-elípticos, base oblíqua, ápice obtuso, arredondado ou emarginado e mucronulado, face adaxial glabra a glabrescente, face abaxial puberulenta, margem curtamente ciliada, nervação broquidódroma, nervuras proeminentes em ambas as faces. Racemos 13-30 cm compr., axilares, congestos e com flores usualmente agrupadas no ápice; brácteas 2,5-3 × 1,5-2 cm, obovais, cuculadas, tardiamente caducas; pedicelo $4-6 \mathrm{~mm}$ compr.; botões 13-16 × 08-11 mm, obovoides. Flores 1,5-2,9 cm compr., simétricas; sépalas 13-15 × 6-9 mm, obovais, arredondadas; pétalas 1,5-2,3 × 1,3-1,8 cm, obovais; estames medianos com filetes 2,5-3,6 mm compr. e anteras 3,3-4,9 mm compr., estames abaxiais com anteras anisomórficas, estame centro-abaxial com filete 6,8-8,2 mm compr. e antera 3,5-4,8 mm compr., 2 estames latero-abaxiais com filetes $3-4,5 \mathrm{~mm}$ compr. e anteras 8-11,6 mm compr., rostro ca. $1 \mathrm{~mm}$ compr.; ovário 1-1,7 cm compr., puberulento, estilete 5-6 mm compr., estipe 2-4 mm compr. Frutos 12-16 × 1,6-2,3 cm, oblongos, 2-alado lateralmente, castanho-escuros, glabros, indeiscentes. Sementes 5-7 × 4-6 mm, bisseriadas, rômbicas, castanhas.

Material examinado: BRASIL. GoiÁs: Mossâmedes, ao lado da casa da sede do Parque, 31-III-2011, fl., M.J. Silva 3531 (UFG); idem, 3-III-2012, fl., M.M. Dantas 137 (UFG).

Material adicional examinado: BRASIL. GoIÁs: Leopoldo de Bulhões, no lado esquerdo da entrada da cidade, 8-XII-2011, fr., M.M. Dantas 66 (UFG);
Alto Paraíso de Goiás, Vila São Jorge, 10-III-2012, fl., M.M. Dantas 191 (UFG).

Possui distribuição na América tropical ocorrendo principalmente próximo ou nas margens de rio, savanas sazonalmente úmidas, áreas perturbadas, margens de estradas, e ainda como invasora em pastagens e plantações (Irwin \& Barneby 1982). No Brasil ocorre em todas as regiões e em praticamente todos os Estados (Souza \& Bortoluzzi 2012).

Senna alata é reconhecida pelas estípulas triangulares com base assimétrica e provavelmente nectarífera, racemos com flores agrupadas no ápice com brácteas amarelas e petaloides e frutos 2-alados lateralmente. No PESD foi coletada nos arredores da sede em local perturbado florescendo em março.

2. Senna corifolia var. caesia (Taub. ex Harms) H.S. Irwin \& Barneby, Mem. New York Bot. Gard. 35: 222. $1982 \equiv$ Cassia caesia Taub. ex Harms, Repert.

Spec. Nov. Regni Veg. 24: 123. 1924.

Figura 1f-k

Arbusto 1-2,5 m alt.; caule e ramos glabros a pubescentes. Estípulas 1-1,7 × 2-4,5 cm, reniformes, coriáceas, persistentes. Folhas 5-15,5 cm compr.; pecíolo 2-4 cm compr.; nectários extraflorais ovoides a cônicos, entre todos os pares de folíolos, sésseis; raque 3-11,5 cm compr.; segmentos interfoliolares 1,5-2,5 cm compr., folíolos 3-5 pares 3-8,6 $\times 1,2-3,5 \mathrm{~cm}$, oblongos, raramente oblongo-elípticos, ápice obtuso ou emarginado e mucronulado, base assimétrica a cordado-assimétrica, face adaxial glabra, face abaxial glabrescente, margem não ciliada, cartáceos a coriáceos; nervação broquidódroma, nervuras proeminentes em ambas as faces. Panículas $12-25 \mathrm{~cm}$ compr., terminais, raramente axilares, laxas; brácteas não vistas; pedicelo 1,2-2 cm compr., com nectário ovoide a cônico, séssil ou subséssil; botões 1-1,5 × 0,7-1 cm, ovoides a elipsoides. Flores 2,7-5,5 cm compr., simétricas; sépalas $0,4-2 \times 0,4-1,5 \mathrm{~cm}$, ovais a obovais; pétalas 1,5-3,5 $\times 1,5-2,5 \mathrm{~cm}$, obovais; estames medianos com filetes 2-3 mm compr., anteras 5-7 mm compr., 


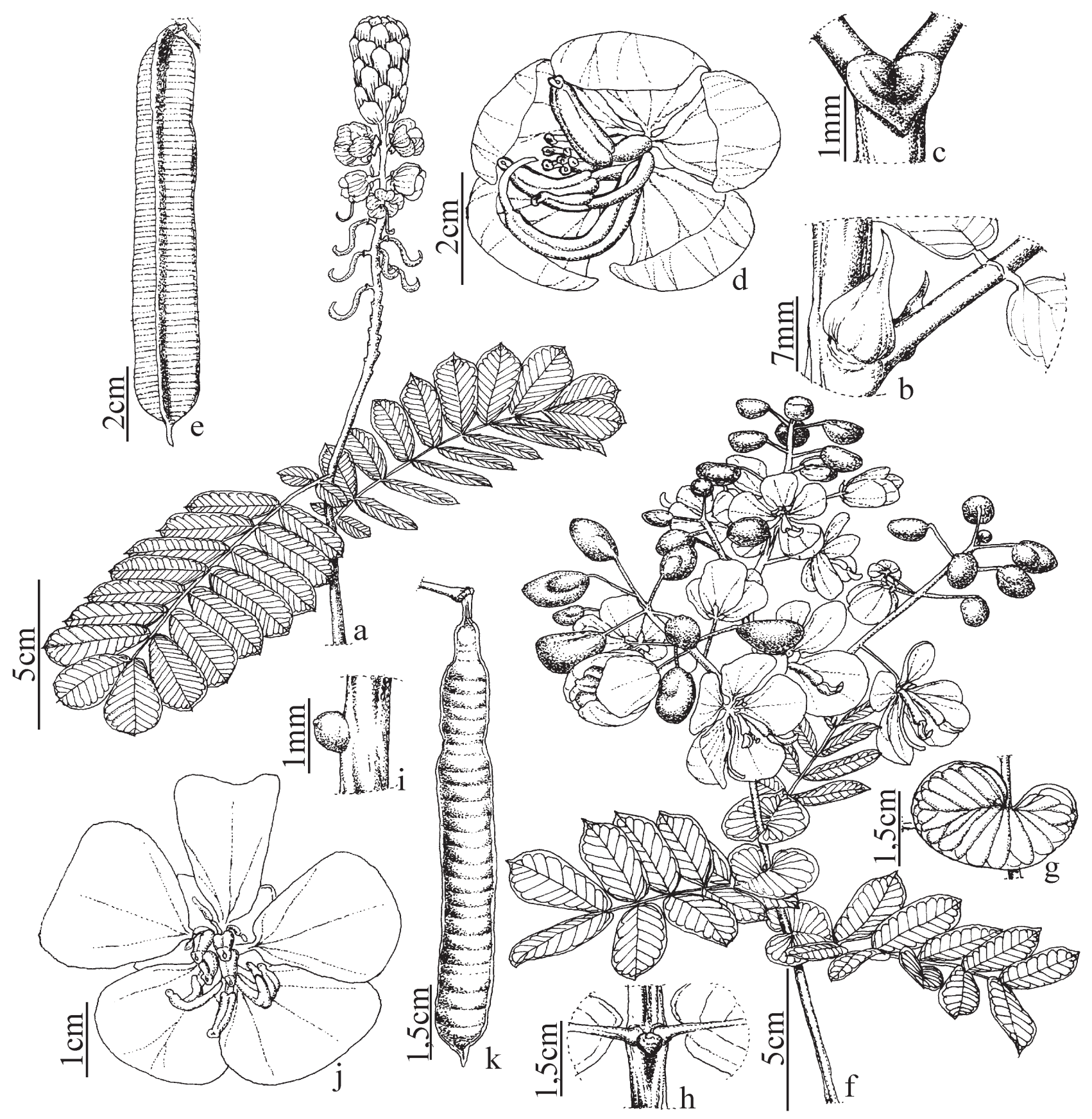

Figura 1. Espécies de Senna do Parque Estadual da Serra Dourada, GO, Brasil. a-e. Senna alata. a. Ramo florido. b. Estípula. c. Seta da terminação foliar. d. Flor. e. Fruto. f-k. S. corifolia var. caesia. f. ramo florido. g. estípula. h. nectário foliar. i. nectário do pedicelo. j. flor. k. fruto. (a-d: M.M. Dantas 137; e: M.M. Dantas 66; f-j: M.J. Silva 351; k: M.M. Dantas 33).

Figure 1. Senna species from Parque Estadual da Serra Dourada, Goiás State, Brazil. a-e. Senna alata. a. Flowering branch. b. Stipule. c. Seta of foliar termination. d. Flower. e. Fruit. f-k. S. corifolia var. caesia. f. Flowering branch. g. Stipule. h. Foliar nectary. i. Nectary of pedicel. j. Flower. k. Fruit. (a-d: M.M. Dantas 137; e: M.M. Dantas 66; f-j: M.J. Silva 351; k: M.M. Dantas 33). 
estames abaxiais com anteras anisomórficas, estame centro-abaxial com filete 4-5,2 mm compr. e antera 5,8-7 mm compr., 2 estames latero-abaxiais com filetes 11-13 mm compr. e anteras $10-12 \mathrm{~mm}$ compr., rostro 0,8-1 mm compr.; ovário 1-1,7 cm compr., seríceo, estilete $9-11 \mathrm{~mm}$ compr., estipe 3-5 mm compr. Frutos 9,5-12 × 0,8-1 cm, oblongos, planos, castanhos a vináceos, pubescentes, tardiamente deiscentes. Sementes 5-6 × 1,5-2,5 mm, unisseriadas, oblongas a elipsoidais, castanhas.

Material examinado: BRASIL. GoiÁs: Mossâmedes, imediações da Pedra Goiana, 26-III-2011, fl., M.J. Silva 3513 (UFG); idem, 26-VIII-2011, fr., M.M. Dantas 5 (UFG); idem, 29-X-2011, fr., M.M. Dantas 33 (UFG); Próximo a rochas do lado esquerdo do Areal, $16^{\circ} 04^{\prime} 38,5 " \mathrm{~S}, 50^{\circ} 11^{\prime 2} 24^{\prime \prime} \mathrm{W}, 992 \mathrm{~m}$ s.n.m., 30-IV-2011, fl., M.J. Silva 3616 (UFG); idem, ibidem, M.J. Silva 3617 (UFG); idem, ibidem, M.J. Silva 3624 (UFG); Goiás Velho, 27-V-2011, fr., M.J. Silva 3671 (UFG).

Material adicional examinado: BRASIL. GoIÁs: Alto Paraíso de Goiás, Serra do Pouso Alto, 9-III-2012, fl., M.M. Dantas 159 (UFG); idem, 1357'39,5"S, $47^{\circ} 28 ' 25,1^{\prime \prime} \mathrm{W}, 1428 \mathrm{~m}$, cerca de $3 \mathrm{~km}$ após o cruzeiro lado esquerdo da estrada de Alto Paraíso a Teresina de Goiás, 20-IV-2012, fl., M.M. Dantas 238 (UFG).

Táxon brasileiro registrado para os Estados de Goiás e Minas Gerais (Irwin \& Barneby 1982) entre 800 e 1.600 m.s.m., crescendo em áreas serranas e de chapadas do Cerrado s.l. usualmente próximo a afloramentos rochosos. Neste estudo foi coletada em ambientes similares a de sua distribuição original.

Irwin \& Barneby (1982) reconheceram para Senna corifolia duas variedades (a variedade caesia e a típica) diferenciadas pelo número e forma dos folíolos. Senna corifolia var. corifolia pode ser reconhecida pelas folhas com dois pares de folíolos orbiculares, enquanto que Senna corifolia var. caesia possui folhas com três a cinco pares de folíolos oblongos. A variedade típica é endêmica do Estado de Goiás (Chapada dos Veadeiros, Serra do Cocal), enquanto que a variedade caesia ocorre nos Estados de Goiás e de Minas Gerais. Floresce em março e abril e frutifica de maio a outubro.

Senna corifolia var. caesia é um dos táxons registrados neste estudo de mais fácil reconhecimento pelas suas estípulas reniformes, coriáceas e amplas $(1-1,7 \times 2-4,5 \mathrm{~cm})$, além de folíolos oblongos, coriáceos e lustrosos na face adaxial e flores com nectário ovoide ou cônico no pedicelo.
3. Senna georgica H.S. Irwin \& Barneby, Mem. New York Bot. Gard. 35: 193. 1982 三 Cassia hoffmannseggii var. gardneriana Benth., Fl. Bras. 15(2): 104. 1870.

Figura 2a-d

Arbustos a arvoretas $2-5 \mathrm{~m}$ alt.; ramos curtamente estrigilosos a glabrescentes. Estípulas 2,3-6,2 $\times 0,8-1,1 \mathrm{~mm}$, lineares, caducas. Folhas 5,7-13,5 cm compr., pecíolo 3-7 cm compr.; nectário extrafloral falóide, séssil, entre o primeiro par de folíolos; raque 2,7-6,5 cm compr.; segmentos interfoliolares 2,7-6,5 cm compr., folíolos 2 pares, 6,5-18 $\times 3,3-8 \mathrm{~cm}$, ovais, oval-elípticos ou elípticos, base obtusa ou cuneada, ápice acuminado, margem não ciliada, face adaxial glabra, face abaxial curtamente estrigilosa, nervação broquidódroma, membranáceos, nervuras proeminentes em ambas as faces. Panículas 10-25 cm compr., laxas, terminais; brácteas 3-5 × 0,5-1 mm, linear-lanceoladas, caducas; pedicelo 2-4 cm compr.; botões 5-10 $\times 5-9 \mathrm{~mm}$, obovoides a globosos. Flores 4,4-7,7 cm compr.; assimétricas; sépalas 5-10 × 4-8 $\mathrm{mm}$, ovais a oblongo-obovais; pétalas 2,2-3,7 × 1,4-1,9 cm, obovais ou oblongas; estames medianos com filetes 3-4 mm compr., anteras 6-7 mm compr., estames abaxiais com anteras anisomórficas, estame centro-abaxial com filete $7-10 \mathrm{~mm}$ compr. e antera 9-10 mm compr., 2 estames latero-abaxiais com filetes 3-8 mm compr. e anteras 9-11 mm compr., rostro 1,8-2 mm compr.; ovário 3-3,5 cm compr., estrigiloso, estilete $2-3 \mathrm{~mm}$ compr., estipe $5-8 \mathrm{~mm}$ compr. Frutos 12-20 × 0,5-0,6 cm, linear-oblongos, planos, enegrecidos a amarronzados, curtamente estrigosos, tardiamente deiscentes. Sementes 3-5 × 2,5-3 mm, unisseriadas, oblongas a oblongo-elípticas, castanhas.

Material examinado: BRASIL. GoIÁs: Mossâmedes, Margem do Córrego do Piçarrão, 2-III-2012, fl., M.M. Dantas 110 (UFG).

Material adicional examinado: BRASIL. GoIÁs: Goiânia, cerca de $16 \mathrm{~km}$ da cidade na margem direita da GO-06, 14-VI-1968, fl., J.A. Rizzo \& A. Barbosa 1496 (UFG); idem, Morro do Mendanha na estrada para Trindade, 2-IX-1968, fr., J.A. Rizzo \& A. Barbosa 2033 (UFG); idem, lado esquerdo da GO-2 em direção a Bela Vista nas proximidades do rio Meia Ponte, V-IX-1968, fr., J.A. Rizzo \& A. Barbosa 2178 (UFG); Monte Alegre, Fazenda Nica, 31-X-2000, fl., F.C.A. Oliveira et al. 1170 (UFG, IBGE). 
Espécie sulamericana registrada para a Bolívia, Brasil e Guianas habitando margens de florestas e clareiras (Irwin \& Barneby 1982). No Brasil é citada para as regiões Centro-Oeste (DF, GO, MS e MT), Norte (AM, PA e TO) e Nordeste (AL, BA, CE, MA, PB, PE, PI e RN), (Souza \& Bortoluzzi 2012). Neste estudo foi coletada na borda da floresta estacional acima do Córrego do Piçarrão e da Fazenda Quinta da Serra.

Senna georgica é espécie facilmente reconhecida entre as demais do PESD pelas folhas com dois pares de folíolos largamente oval-elípticos a elípticos com ápices conspicuamente acuminados e nectário faloide apenas no primeiro par. Floresce e frutifica de junho a outubro, porém, também foi coletada com flores em março.

4. Senna multijuga subsp. multijuga (Rich.) H.S. Irwin \& Barneby, Mem. New York Bot. Gard. 35: 492. $1982 \equiv$ Cassia multijuga Rich., Actes Soc. Hist. Nat. Paris 1: 108. 1792.

Figura 2e-i

Árvores 5-15 m alt.; ramos tomentoso-ferrugíneos. Estípulas 5-8 × 0,8-1,2 mm, triangulares com base conspicuamente dilatada, tardiamente caducas. Folhas 10,3-18,6 cm compr., pecíolo 1,3-2,6 cm compr.; nectários extraflorais lanceoloides, ovoides ou fusiformes, sésseis, no primeiro e nos pares distais de folíolos; raque 9-16 cm compr.; segmentos interfoliolares $0,5-1,2 \mathrm{~cm}$ compr., folíolos 18-24 pares, 1,4-3,3 $\times 0,5-1,2 \mathrm{~cm}$, oblongos ou oblongo-elípticos raramente oblanceolados, base oblíqua, ápice obtuso, arredondado ou retuso e mucronulado, margem ciliada, cartáceos, glabrescentes a curtamente seríceos em ambas as faces, nervação broquidódroma, nervuras pouco proeminentes a impressas em ambas as faces. Panículas e/ou racemos $5-20 \mathrm{~cm}$ compr., laxos, axilares e, ou terminais; brácteas 3-6 $\times$ 2-3 mm, ovais, caducas; pedicelo 1,5-3,3 cm compr.; botões 3-5 × 3-4 mm, globosos. Flores 2,7-5,5 cm compr., assimétricas; sépalas 5-8 × 4-6 mm, oboval-orbiculares a elípticas, ápice obtuso a arredondado; pétalas 1,2-2,0 × 0,8-1,2 cm, obovais, a abaxial falcado-oboval; estames medianos com filetes 1,5-2 $\mathrm{mm}$ compr., anteras 6-8 $\mathrm{mm}$ compr., estames abaxiais com anteras isomórficas, estame centro-abaxial com filete 3-6 mm compr. e antera 7-9 mm compr., 2 estames latero-abaxiais com filetes 2,5-6 mm compr. e anteras 9-10 mm compr., rostro 1,5-2,2 mm compr.; ovário 1,2-1,6 cm compr., séssil, seríceo, estilete $2-3 \mathrm{~mm}$ compr. Frutos 7-16 $\times 0,8-1,5 \mathrm{~cm}$, lineares, planos, castanho-escuros, glabrescentes a puberulentos, tardiamente deiscentes. Sementes 5-7 × 1,5-2,5 mm, unisseriadas, oblongas, castanho-claras.

Material examinado: BRASIL. GoIÁs: Mossâmedes, antes do Córrego do Piçarrão no lado direito próximo a floresta semidecidual depois da porteira, 27-IV-2012, fl., M.M. Dantas 249 (UFG).

Material adicional examinado: BRASIL. Goiás: Pirenópolis, lado direito da estrada que dá acesso Serra dos Pireneus na saída da cidade, 18-XI-2011, fl., fr., M.M. Dantas 53 (UFG); idem, ibidem, M.M. Dantas 54 (UFG).

Táxon com distribuição desde o México até o Paraguai ocorrendo em florestas de várzeas ou terra firme, margem de rios e riachos nos cerrados e em áreas perturbadas (Irwin \& Barneby 1982). No Brasil é referida de Norte a Sul usualmente associada a florestas estacionais sazonalmente secas ou litorâneas.

Irwin \& Barneby (1982) reconheceram para Senna multijuga três subespécies (doylei, lindleyana e multijuga) e as variedades lindleyana para a subespécie de mesmo epíteto, além de multijuga, peregrinatrix e verrucosa para a subespécie multijuga. Por apresentar folhas com 18 a 24 pares de folíolos, estípulas triangulares com base conspicuamente dilatada e nectários nos primeiros e distais pares de folíolos o táxon aqui encontrado corresponde a Senna multijuga subsp. multijuga.

Dentre os táxons estudados $S$. multijuga subsp. multijuga é o único com folhas de 18-24 pares de folíolos, as quais associadas ao hábito arbóreo, a torna facilmente reconhecida. Coletada com flores em abril e com flor e fruto em novembro.

5. Senna obtusifolia (L.) H.S. Irwin \& Barneby, Mem. New York Bot. Gard. 35: 252. $1982 \equiv$ Cassia obtusifolia L., Sp. P1. 1: 377. 1753.

Figura 3a-c

Subarbustos ou arbustos 0,3-1,2 m alt.; ramos glabrescentes a esparso-tomentosos. Estípulas $8-15 \times 0,5-1,2 \mathrm{~mm}$, lineares a linear-lanceoladas, persistentes. Folhas 3,3-6,3 cm compr.; pecíolo 1,5-3,5 cm compr.; nectário extrafloral fusiforme, séssil ou subséssil, no primeiro ou raramente no segundo par de folíolos; raque 1,8-2,8 cm compr.; segmentos interfoliolares 0,7-1,5 compr.; folíolos 2-3 pares, $2-4,1 \times 1,5-2,8 \mathrm{~cm}$, estreito-obovais a obovais, base oblíqua, ápice obtuso ou arredondado e mucronulado, face adaxial glabra a puberulenta, face abaxial 


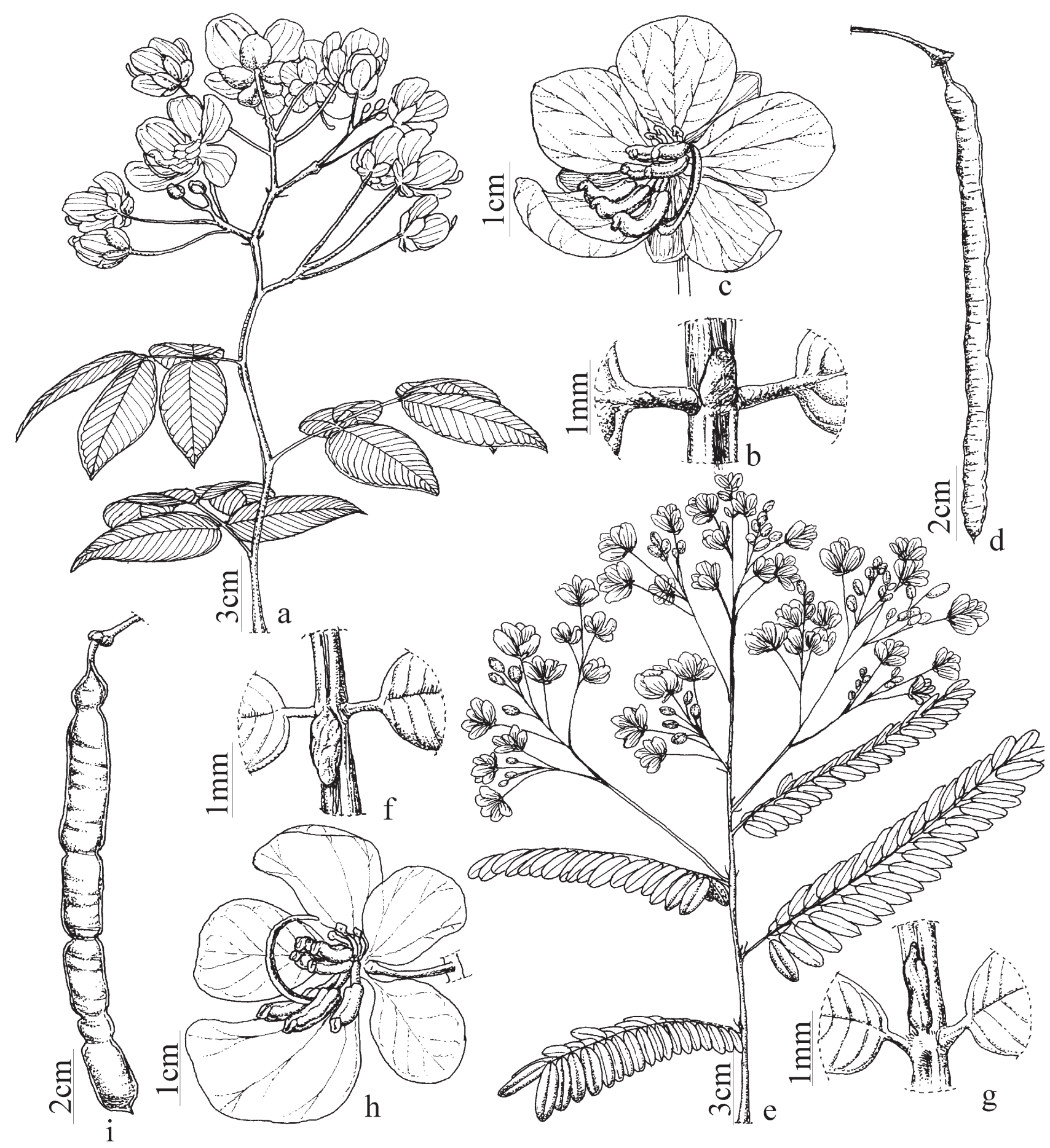

Figura 2. Espécies de Senna do Parque Estadual da Serra Dourada, GO, Brasil. a-d. Senna georgica. a. Ramo florido. b. Detalhe do nectário foliar. c. Flor. d. Fruto. e-i. S. multijulga subsp. multijuga. e. Ramo florido. f. Detalhe do nectário dos folíolos proximais. g. Detalhe do nectário dos folíolos distais. h. Flor. i. Fruto. (a-c: M.M. Dantas 110; d: J.A. Rizzo \& A. Barbosa 2033; e-h: M. M. Dantas 249; i: M.M. Dantas 54).

Figure 2. Senna species from Parque Estadual da Serra Dourada, Goiás State, Brazil. a-d. Senna georgica. a. Flowering branch. b. Detail of foliar nectary. c. Flower. d. Fruit. e-i. S. multijulga subsp. multijuga. e. Flowering branch. f. Nectary of basal leaflets. g. Nectary of distal leaflets. h. Flower. i. Fruit. (a-c: M.M. Dantas 110; d: J.A. Rizzo \& A. Barbosa 2033; e-h: M.M. Dantas 249; i: M.M. Dantas 54). 
curto-serícea, margem ciliada, cartáceos, nervação broquidódroma, nervuras pouco proeminentes em ambas as faces. Fascículos 1-3(-4)-floros, axilares, sésseis ou pedunculados (pedúnculo 1-5 mm compr.); brácteas 2-4 × 0,2-0,4 mm, linear-lanceoladas, persistentes; pedicelo 1-1,5 cm compr.; botões 5-7 $\times 3-5 \mathrm{~mm}$, globosos ou orbiculoides. Flores 2-3 cm compr., assimétricas; sépalas 5-9 $\times 3-5 \mathrm{~mm}$, ovais a obovais; pétalas $10-15 \times 4-8 \mathrm{~mm}$, obovais, oblongas ou oblongo-obovais; estames medianos com filetes 1,7-2 mm compr., anteras 3-4 mm compr., estames abaxiais com anteras isomórficas, estame centro-abaxial com filete 1,5-2 $\mathrm{mm}$ compr. e antera 3,2-4 mm compr., 2 estames latero-abaxiais com filetes $2-3 \mathrm{~mm}$ compr. e anteras $3-4 \mathrm{~mm}$ compr., rostro 0,7-1 mm compr.; ovário 1-1,5 cm compr., seríceo, séssil, estilete $3-4 \mathrm{~cm}$ compr. Frutos $8-15 \times 0,2-0,3 \mathrm{~cm}$, cilíndricos, fortemente curvos, castanho-escuros, glabros, indeiscentes. Sementes $4-4,8 \times 2-2,5 \mathrm{~mm}$, unisseriadas, irregularmente rômbicas, castanhas.

Material examinado: BRASIL. GoIÁs: Mossâmedes, na borda da estrada, próximo ao Córrego do Piçarrão, $16^{\circ} 06^{\prime} 15,8^{\prime \prime} \mathrm{S}, 50^{\circ} 11^{\prime} 4,4^{\prime \prime} \mathrm{W}, 724$ m.s.m., 29-IV-2011, fl., fr., L.R. Naves 58 (UFG); idem, 2-III-2012, fl., fr., M.M. Dantas 100 (UFG).

Material adicional examinado: BRASIL. GoIÁs: Silvânia, estrada de acesso a Floresta Nacional de Silvânia, 4-IV-2012, fl., fr., M.M. Dantas 201 (UFG); idem, ibidem, M.M. Dantas 202 (UFG).

Espécie americana com ocorrência desde os Estados Unidos até a Argentina, porém, é introduzida na África e Ásia (Irwin \& Barneby 1982). Em sua área de abrangência habita diversos ambientes como Caatinga, Cerrado, Mata Atlântica, floresta tropical sazonalmente seca, florestas úmidas, entre outras, sempre associada a locais perturbados e também em pastagens ou áreas agricultáveis. No Brasil está representada de Norte a Sul.

Assemelha-se morfologicamente a $S$. pilifera com a qual compartilha o hábito subarbustivo, as inflorescências fasciculadas e as estípulas persistentes. Em S. obtusifolia os ramos são glabrescentes a esparso tomentosos (vs. ramos hirsutos em S. pilifera), as folhas possuem nectário usualmente no primeiro par de folíolo ( $v s$. em todos os pares), as estípulas e frutos são curvos (vs. retos). Floresce e frutifica em março e abril.
6. Senna occidentalis (L.) Link, Handbuch 2: 140. $1829 \equiv$ Cassia occidentalis L., Sp. PL. 377. 1753. Figura 3d-g

Subarbustos ou arbustos 1-2,5 m alt.; ramos glabros a glabrescentes. Estípulas caducas. Folhas 7-14,7 cm compr.; pecíolo 3-4,7 cm compr.; nectário extrafloral peciolar ovoide, séssil; raque $4-11 \mathrm{~cm}$ compr; segmentos interfoliolares 1,5-2,6 cm compr.; folíolos 4-6 pares, 2,5-7,5 × 1,3-2,2 cm, elípticos, oval-elípticos ou oblongo-elípticos, base oblíqua, ápice acuminado, glabros em ambas as faces, margem ciliada, membranáceos; nervação broquidódroma, nervuras pouco proeminentes a impressas em ambas as faces. Racemos 0,5-1 cm compr., (1-)2-4(5)-floros, axilares; brácteas 9-18 × 3-5 mm, ovais a lanceoladas, tardiamente caducas; pedicelo $8-14 \mathrm{~mm}$ compr.; botões 9-5 × 4-7 mm, globosos. Flores 2-3,4 cm compr., simétricas; sépalas 7-11 × 4-6 mm, obovais a oblongo-elípticas; pétalas 15-20 × 8-14 mm, obovais ou oblongo-obovais; estames medianos com filetes 2-4 mm compr., anteras $4-5 \mathrm{~mm}$ compr., estames abaxiais com anteras anisomórficas, estame centro-abaxial reduzido a estaminódio com filete 3-4 mm compr. e antera 2-4 mm compr., 2 estames latero-abaxiais com filetes $5-7 \mathrm{~mm}$ compr. e anteras 5-6 mm compr. com rostro 1-1,5 mm compr.; ovário 9-11 mm compr., séssil, tomentoso, estilete 3-4 mm compr. Frutos 7-11 $\times 0,5-1 \mathrm{~cm}$, planos, linear-oblongos, ligeiramente curvos, castanho-escuros, glabrescentes a puberulentos, indeiscentes. Sementes 4-5 × 3-4 mm, unisseriadas, obovais a elipsoidais, oliváceas.

Material examinado: Brasil. GoIÁs: Mossâmedes, sopé da serra próximo ao Córrego do Piçarrão, $16^{\circ} 06^{\prime} 15,8^{\prime \prime S}, 50^{\circ} 11^{\prime} 4,4^{\prime \prime} \mathrm{W}, 724$ m.s.m., 2-III-2012, fl., fr., M.M. Dantas 94 (UFG).

Material adicional examinado: BRASIL. GoIÁs: Anápolis, no terreno baldio em frente ao condomínio Chácara Vale das Brisas, 18-XII-2011, fl., fr., J.P. Santos 261 (UFG); Goiânia, Setor Parque Anhanguera II, 3-IV-2012, fr., J.P. Santos 428 (UFG).

Espécie paleotropical amplamente distribuída nos neotrópicos (Irwin \& Barneby 1982). No Brasil ocorre de Norte a Sul como ruderal, invasora de culturas e também associada a locais perturbados.

Pelas folhas com folíolos elípticos com ápices acuminados e com um nectário no pecíolo, caule e ramos conspicuamente vináceos a verde vináceos e glabros a glabrescentes Senna occidentalis é facilmente reconhecida e distinguível das demais 


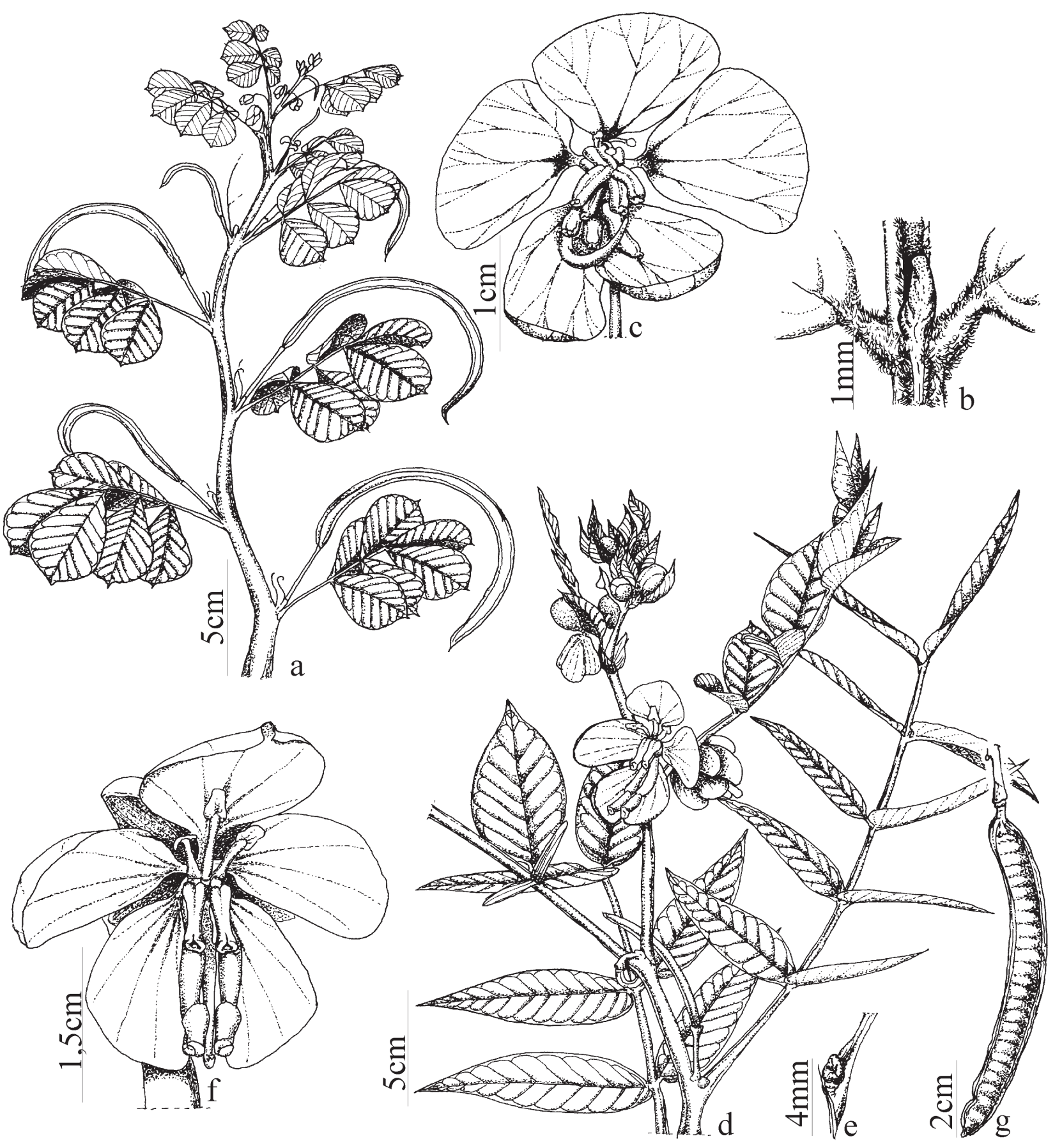

Figura 3. Espécies de Senna do Parque Estadual da Serra Dourada, GO, Brasil. a-c. Senna obtusifolia. a. Ramo fértil. b. Nectário foliar. c. Flor. d-g. S. occidentalis. d. Ramo florido. e. Nectário peciolar. f. Flor. g. Fruto. (a-c: M.M. Dantas 100; d-g: M.M. Dantas 94).

Figure 3. Senna species from Parque Estadual da Serra Dourada, Goiás State, Brazil. a-c. Senna obtusifolia. a. Fertile branch. b. Foliar nectary. c. Flower. d-g. S. occidentalis. d. Flowering branch. e. Petiolar nectary. f. Flower. g. Fruit. (a-c: M.M. Dantas 100; d-g: M.M. Dantas 94). 
espécies estudadas. Pode ser confundida com S. hirsuta, não encontrada neste estudo, por ambas possuírem folíolos semelhantes (oval-elípticos a oblongo-elípticos com ápices acuminados) e nectário peciolar. No entanto, $S$. hirsuta possui ramos hirsutos, enquanto que em $S$. occidentalis os ramos são glabros a glabrescentes. No PESD foi encontrada na borda da estrada de acesso a sede do Parque antes do Córrego do Piçarrão. Floresce e frutifica de dezembro a abril.

7. Senna pendula var. glabrata (Vogel) H.S. Irwin \& Barneby, Mem. New York Bot. Gard. 35: 382. $1982 \equiv$ Cassia indecora var. glabrata Vogel, Gen. Cass. Syn. 19. 1837.

Figura 4a-d

Arbustos 1-3 m alt.; ramos glabros a glabrescentes, pendentes ou apoiantes. Estípulas caducas. Folhas 4-8 cm compr.; pecíolo 2-3,5 cm compr.; nectário extrafloral ovoide a oblongo-ovoide, séssil ou subséssil, nos dois primeiros pares de folíolos ou somente no primeiro par; raque $2-4,5 \mathrm{~cm}$ compr.; segmentos interfoliolares $0,6-1,5 \mathrm{~cm}$ compr.; folíolos 4-5 pares, 1,8-4 × 0,8-1,6 cm, obovais a oblongo-elípticos, base assimétrica, ápice obtuso a arredondado e mucronulado, glabros em ambas as faces, margem ciliada na parte basal; nervação broquidódroma, nervuras pouco proeminentes em ambas as faces. Racemos 7-10 cm compr., laxos, axilares, corimbiformes; brácteas 2-4 × 0,2-0,5 mm, linear-lanceoladas, caducas; pedicelo $1,2-2,5 \mathrm{~cm}$ compr.; botões 5-8 $\times$ 4-6 mm, obovoides. Flores 1,8-4,7 cm compr., assimétricas; sépalas 0,9-2 $\times 0,6-1 \mathrm{~cm}$, ovais ou oblongo-obovais, ápice arredondado ou obtuso; pétalas $16-22 \times 10-17 \mathrm{~mm}$, largamente obovais, obovais ou oblongo-obovais; estames medianos com filetes 1-1,8 mm compr., anteras 5-6,5 mm compr., estames abaxiais com anteras anisomórficas, estame centro-abaxial com filete $3-5 \mathrm{~mm}$ compr. e antera $18-10 \mathrm{~mm}$ compr., 2 estames latero-abaxiais com filetes $18-22 \mathrm{~mm}$ compr. e anteras $8-10 \mathrm{~mm}$ compr., rostro $0,8-1,5 \mathrm{~mm}$ compr.; ovário 1-1,5 cm compr., glabro, estipitado, estipe 4-5 $\mathrm{mm}$ compr., estilete $5-7 \mathrm{~mm}$ compr. Frutos 8-15 × 0,6-0,9 cm, oblongos, cilíndricos, verde-claros, glabros, indeiscentes. Sementes 4,5-5,5 × 2,8-3,5 mm, bisseriadas, oblongo-elípticas a obovais, castanho-claras a enegrecidas.

Material examinado: BRASIL. GoIÁs: Divisa dos municípios de Mossâmedes ao sul e Goiás ao norte, 1-II-1970, fl., J.A. Rizzo 4709 (UFG); Fazenda Quinta da Serra, 27-IV-2012, fl., M.M. Dantas 248 (UFG); idem, 7-VI-2012, fr., M.M. Dantas 336 (UFG).

Material adicional examinado: BRASIL. GoIÁs: Goiânia, margem direita da BR 153 sentido Brasília a 11 km da cidade de Goiânia, 1-V-1970, fl., J.A. Rizzo 6763 (UFG); a esquerda da estrada de Goiânia para Leopoldo de Bulhões cerca de 10 km de Goiânia, 1-III-1971, fl., J.A. Rizzo 6983 (UFG); Goiatuba, Distrito de Porteirão, na margem do Rio dos Bois, 23-V-1993, fl., V.L.G. Klein et al. 2087 (UFG); Pirenópolis, alto da Serra dos Pireneus na base dos três picos, 11-II-1971, fl., J.A. Rizzo 5957 (UFG); Silvânia, Floresta Nacional de Silvânia, na trilha após a sede, 25-II-2011, fl., M.J. Silva 3441 (UFG).

Espécie referida para o Brasil (no Distrito Federal e Estados da Bahia, Goiás, Mato Grosso, Mato Grosso do Sul, Minas Gerais, Pará, Paraná, Rio de Janeiro, Santa Catarina e São Paulo) e Paraguai (Irwin \& Barneby 1982, Souza \& Bortoluzzi 2012). Habita principalmente no Cerrado s.l., em margens de mata de galeria, áreas perturbadas ou campos sobre solos geralmente areno ou argilo-pedregosos entre $450 \mathrm{e}$ $2.000 \mathrm{~m}$ de altitude.

Os ramos pendentes ou apoiantes associados às folhas com 4-5 pares de folíolos predominantemente obovais e nectários ovoides ou globosos entre os dois pares proximais ou só no primeiro par de folíolos tornam essa espécie facilmente reconhecida. Coletada com flores de fevereiro a maio e com frutos em junho.

8. Senna pilifera (Vogel) H.S. Irwin \& Barneby, Mem. New York Bot. Gard. 35(1): 241. $1982 \equiv$

Cassia pilifera Vogel, Gen. Cass. Syn. 23. 1837. Figura 4e-h

Subarbustos ou arbustos 1-2,5 m alt.; ramos hirsutos entremeados com tricomas tomentosos. Estípulas 6-18 × 0,5-1 mm, linear-lanceoladas, persistentes. Folhas $6-22 \mathrm{~cm}$ compr.; pecíolo 2-7 cm compr.; nectários extraflorais fusiformes, estipitados, (estípite 0,5-1 mm compr.) em todos os pares de folíolos; raque 4-15 mm compr.; segmentos interfoliolares $4-15 \mathrm{~cm}$ compr.; folíolos 2 pares, 2,8-8,6 $\times 1,5-3,6 \mathrm{~cm}$, elíptico-obovais, base oblíqua, ápice obtuso ou retuso e mucronulado, face adaxial serícea a curto tomentosa, face abaxial curto tomentosa, margem ciliada, membranáceos; nervação broquidódroma, nervuras pouco proeminentes em ambas as faces. Fascículos (1)2-4(5)-floros, axilares, pseudoumbelados, pedunculados (pedúnculo 1-3 cm compr.); brácteas 2-3 × 0,8-1,2 mm, ovais, 


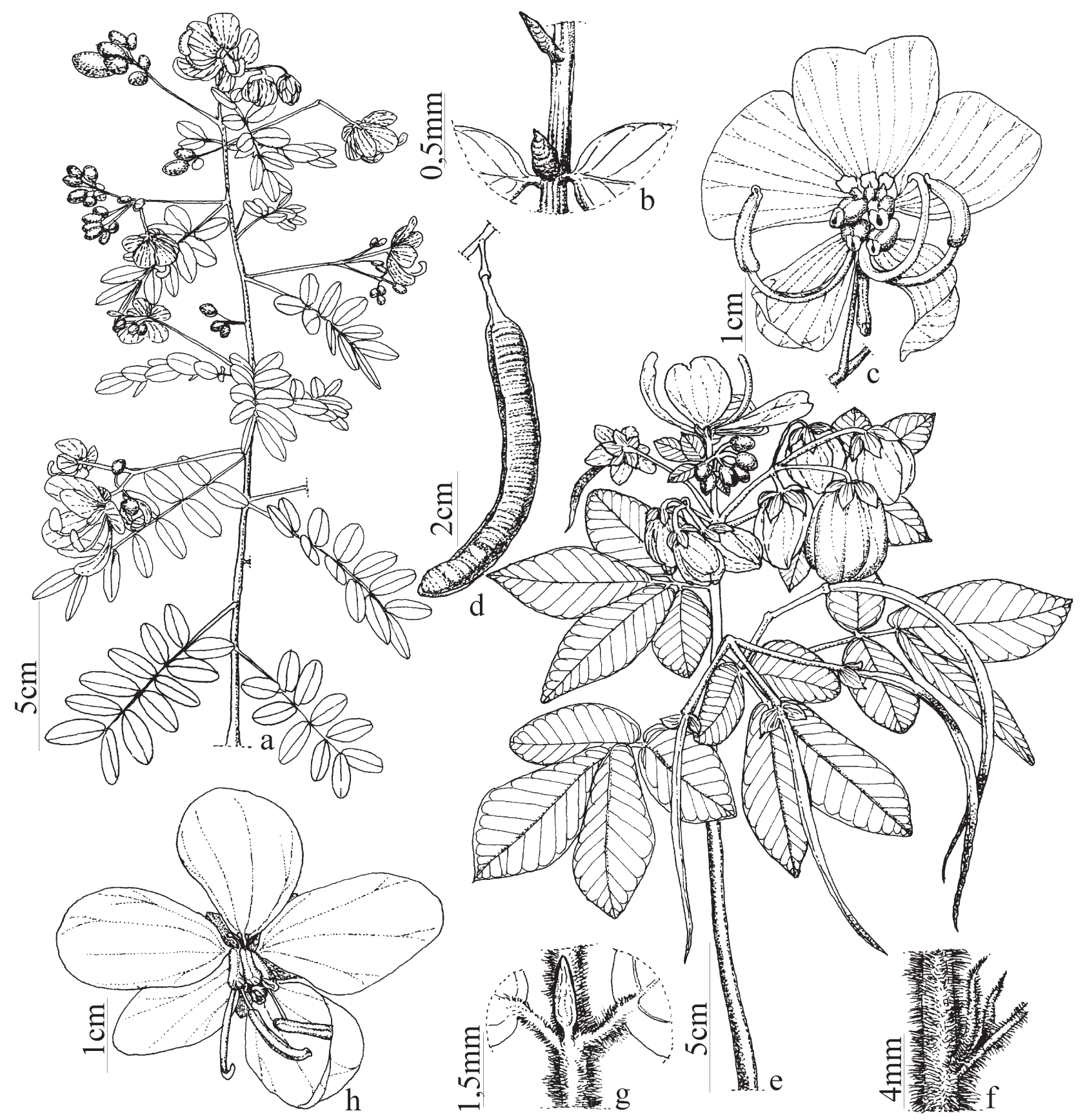

Figura 4. Espécies de Senna do Parque Estadual da Serra Dourada, GO, Brasil. a-d. Senna pendula var. glabrata. a. Ramo florido. b. Nectário foliar. c. Flor. d. Fruto. e-h. S. pilifera. e. Ramo fértil. f. Estípulas. g. Nectário foliar. h. Flor. (a-c: M.M. Dantas 248; d: M.M. Dantas 336; e-h: M.M. Dantas 126).

Figure 4. Senna species from Parque Estadual da Serra Dourada, Goiás State, Brazil. a-d. Senna pendula var. glabrata. a. Flowering branch. b. Foliar nectary. c. Flower. d. Fruit. e-h. S. pilifera. e. Fertile branch. f. Stipules. g. Foliar nectary. h. Flower. (a-c: M.M. Dantas 248; d: M.M. Dantas 336; e-h: M.M. Dantas 126). 
esverdeadas, persistentes a tardiamente caducas; pedicelo 1,5-2,5 cm compr.; botões 6-10 × 4-6 mm, elipsoides. Flores 2,5-5,7 cm compr., assimétricas; sépalas 6-10 × 4-7 mm, ovais a elípticas; pétalas 20-32 $\times 10-20 \mathrm{~mm}$, obovais ou oblongo-obovais, uma adaxial oblongo-elíptica; estames medianos com filetes 2-3,5 mm compr., anteras 4-7 mm compr., estames abaxiais com anteras isomórficas, estame centro-abaxial com filete 5-7 $\mathrm{mm}$ compr. e antera 10-12 mm compr., 2 estames latero-abaxiais com filetes $8-10 \mathrm{~mm}$ compr. e anteras $10-12 \mathrm{~mm}$ compr., rostro 0,8-1 mm compr.; ovário 1,5-2 $\mathrm{cm}$ compr., seríceo, estilete 7-10 mm compr., estipe 1-2 mm compr. Frutos 8-13 × 0,2-0,3 cm, lineares, plano-compresos, levemente curvos, castanhos, curtamente seríceos, indeiscentes. Sementes 2,4-3,2 × 0,7-1 mm, unisseriadas, oblongas a oblongo-elípticas, castanhas.

Material examinado: BRASIL. GoIÁs: Mossâmedes, na base do morro da Asa Delta, $16^{\circ} 03^{\prime} 24,1^{\prime \prime} \mathrm{S}$, 50¹0'39,5"W, 763 m s.n.m., 3-III-2012, fl., fr., M.M. Dantas 125 (UFG); idem, ibidem, M.M. Dantas 126 (UFG); idem, ibidem, M.M. Dantas 127 (UFG).

Espécie registrada desde o México até o Uruguai (Irwin \& Barneby 1982). No Brasil é referida para as regiões Centro-Oeste (DF, GO, MT e MS), Sudeste (MG e SP) e Sul (PR e RS) crescendo em campos, brejos, pastagens, Cerrado s.l., e floresta estacional (Irwin \& Barneby 1982). Neste estudo foi coletada em floresta estacional em local úmido.

Esta espécie assemelha-se morfologicamente a S. obtusifolia conforme discutido nos comentários desta última. Foi encontrada com flores e frutos jovens no mês de março.

9. Senna rugosa (G. Don) H.S. Irwin \& Barneby, Mem. New York Bot. Gard. 35: 188. $1982 \equiv$ Cassia rugosa G. Don, Gen. Hist. 2: 440. 1832.

Figura 5a-d

Arbustos 0,5-1,6 m alt., cespitosos. Caule e ramos jovens curtamente tomentosos. Estípulas 4-6 $\times 0,3-0,5 \mathrm{~mm}$, linear-lanceoladas a subuladas, tardiamente caducas. Folhas 4-14 cm compr.; pecíolo 3-12 mm compr.; nectários extraflorais ovoides a cônicos, sésseis, em todos os pares de folíolos; raque 1-2 cm compr.; segmentos interfoliolares 1-2 cm compr.; folíolos 2 pares, 3,5-8 × 1,4-2,8 cm, oblongo-obovais a raramente oval-oblongos ou oblongo-elípticos, base oblíqua, ápice obtuso ou emarginado e mucronulado, face adaxial glabrescente a pubescente, face abaxial curtamente tomentosa, nervação broquidódroma, margem ciliada, nervuras proeminentes na face abaxial. Panículas terminais ou racemos axilares, $6-15 \mathrm{~cm}$ compr., laxas; brácteas 3-6 × 1-4 mm compr., ovais, raramente linear-lanceoladas, tardiamente caducas; pedicelo 2-4 cm compr.; botões 6-8 $\times 4-7 \mathrm{~mm}$, orbiculoides. Flores 3,8-7,5 cm compr., assimétricas; sépalas 6-10 × 4-7 mm, ovais a elípticas; pétalas 20-32 × 10-20 mm, obovais ou oblongo-obovais, uma adaxial oblongo-elíptica; estames medianos com filetes 1,5-2 mm compr., anteras 5-6 mm compr., estames abaxiais com anteras isomórficas, estame centro-abaxial com filete 4-5 mm compr. e antera 9-10 $\mathrm{mm}$ compr., 2 estames latero-abaxiais com filetes 3-3,5 mm compr. e anteras 8-9 mm compr., rostro 1,5-2 mm compr.; ovário 13-22 mm compr., curtamente setoso, estipitado, estípite 2-5 mm compr., estilete 6-8 mm compr. Frutos 5,5-8,5 × 1,5-2,0 cm, oblongos, cilíndricos, negros, puberulentos, indeiscentes. Sementes 5-8 $\times$ 4-6 mm, obovoides, bisseriadas, castanhas.

Material examinado: BRASIL. GoIÁs: Mossâmedes, Parque Estadual da Serra Dourada, estrada para o mirante, 25-III-2011, fl., M.J. Silva 3479 (UFG); Antes da porteira que dá acesso a sede nas imediações do morro, 30-IV-2011, fl., M.J. Silva 3629 (UFG); Imediações do Areal, 27-V-2011, fl., M.J. Silva 3665(UFG).

Material adicional examinado: BRASIL. GoIÁs: Silvânia, a $3 \mathrm{~km}$ do posto da polícia Federal no lado direito da estrada, 25-II-2011, fl., M.J. Silva 3414 (UFG); Leopoldo de Bulhões, entrada da cidade, 8-XII-2011, fl., M.M. Dantas 65 (UFG); Alto Paraíso de Goiás, Sítio Pedrão em campo sujo ao longo do córrego, 21-X-2011, fr., M.J. Silva 3820 (UFG).

Senna rugosa ocorre de Norte a Sul do Brasil e também na Bolívia e Paraguai. Porém é mais frequente no Cerrado onde cresce usualmente em solos pedregosos ou avermelhados e também em beira de estradas ou em matas de galeria (Irwin \& Barneby 1982).

Pode ser reconhecida pelas folhas com dois pares de folíolos com nectários em ambos os pares e frutos cilíndricos e negros quando maduros. Foi coletada com flores de dezembro a maio e com fruto em outubro. 


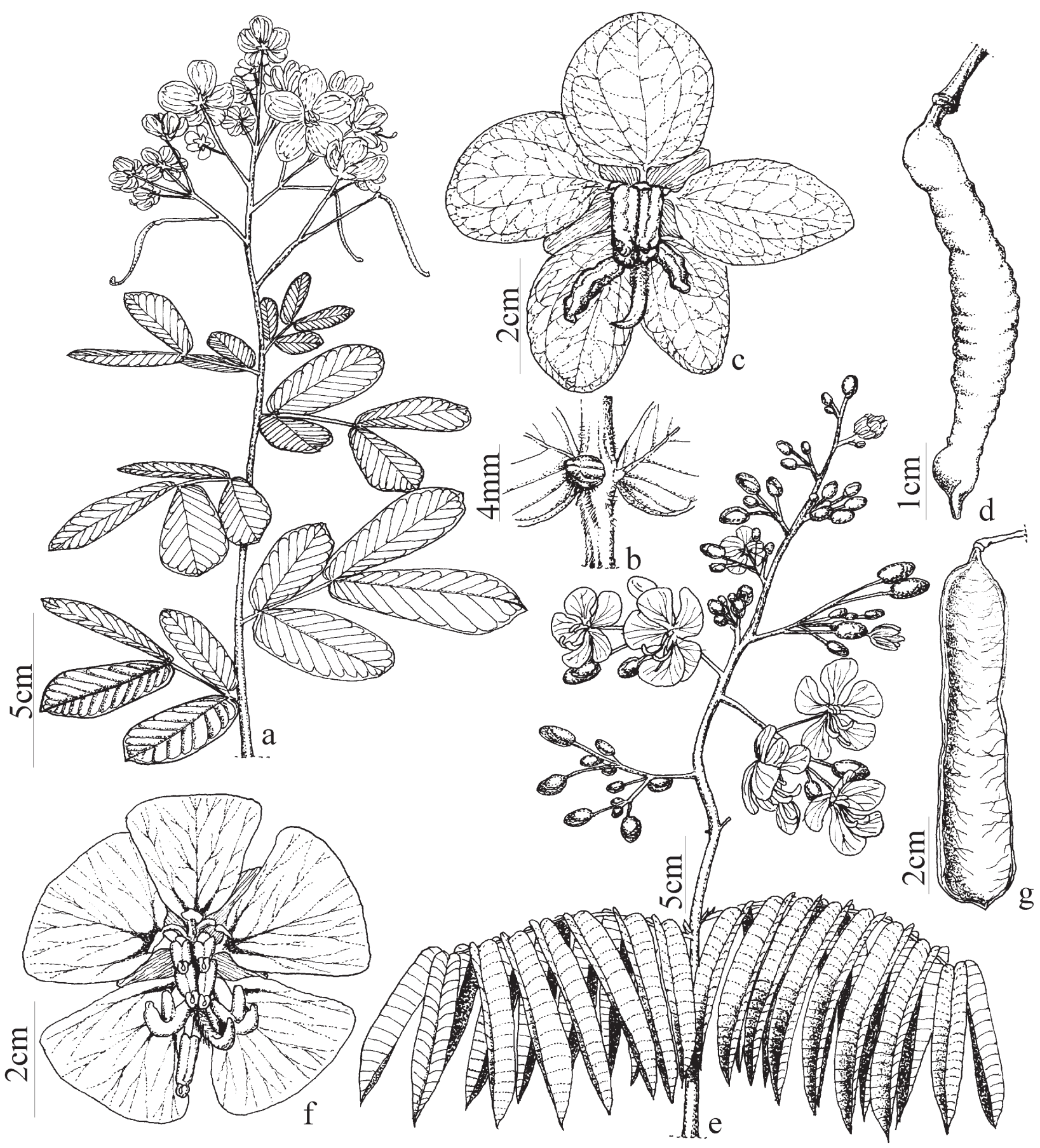

Figura 5. Espécies de Senna do Parque Estadual da Serra Dourada, GO, Brasil. a-d. Senna rugosa. a. Ramo florido. b. Nectário. c. Flor. d. Fruto. e-g. S. silvestris subsp. bifaria. e. Ramo florido. f. Flor. g. Fruto. (a-c: M.J. Silva 3629; d: M.J. Silva 3629; e-g: M.J. Silva 3661).

Figure 5. Senna species from Parque Estadual da Serra Dourada, Goiás State, Brazil. a-d. Senna rugosa. a. Flowering branch. b. Nectary. c. Flower. d. Fruit. e-g. S. silvestris subsp. bifaria. e. Flowering branch. f. Flower. g. Fruit. (a-c: M.J. Silva 3629; d: M.J. Silva 3629; e-g: M.J. Silva 3661). 
10. Senna silvestris subsp. bifaria H.S. Irwin \& Barneby, Mem. New York Bot. Gard. 35: 94.1982 Figura 5e-g

Arbustos a arvoretas 2,5-5 m alt.; ramos curto-tomentosos a pubescentes. Estípulas 4-6 $\times 0,5-1 \mathrm{~mm}$, lineares ou subuladas, tardiamente caducas. Folhas 10,9-35 cm compr.; pecíolo 2,9-9,0 cm compr.; nectários extraflorais ausentes; raque $8-26 \mathrm{~cm}$ compr.; segmentos interfoliolares $1-4,5 \mathrm{~cm}$ compr.; folíolos 4-8 pares, 4-15,5 × 2,5-5,5 cm, ovais, oblongos a elípticos ou lanceolados, base oblíqua, subcordada a arredondada, ápice acuminado, obtuso ou arredondado, margem não ciliada, cartáceos, curto-tomentoso em ambas as faces, nervação broquidódroma, nervuras proeminentes em ambas as faces. Panículas 25-50 cm compr., eixos secundários corimbiformes, laxas, axilares e terminais; brácteas 2-3 $\times 0,5-1,5 \mathrm{~mm}$, ovais ou lanceoladas, caducas; pedicelo 2-4 cm compr.; botões 5-10 $\times 5-9 \mathrm{~mm}$, obovoides a globosos. Flores 3,5-6,5 cm compr., simétricas; sépalas 5-10 × 4-8 mm, ovais a obovais ou suborbiculares; pétalas 1,5-2,0 × 1,5-2,1 cm, obovais; estames medianos com filetes $2-4 \mathrm{~mm}$ compr., anteras 5-6 mm compr., estames abaxiais com anteras anisomórficas, estame centro-abaxial com filete 5-6 mm compr. e antera 6-7 mm compr., 2 estames latero-abaxiais com filetes $5-6 \mathrm{~mm}$ compr. e anteras 6-7 mm compr., rostro 1-1,5 mm compr.; ovário 1-1,5 cm compr., viloso-amarelado lateralmente, estipe 2-3 mm compr., estilete 2,5-3 mm compr. Frutos 8-14,5 × 1,5-2,3 cm, linear-oblongos, planos, vináceos com margens esverdeadas, glabros, tardiamente indeiscentes. Sementes 5,5-7,5 × 2-3 mm, bisseriadas, oblongas a oblanceoladas, castanhas ou amarronzadas.

Material examinado: Brasil GoIÁs: Mossâmedes, próximo a bica na torre de capitação, 27-V-2011, fl., fr., M.J. Silva 3661 (UFG); Cerca de 700 metros após Córrego do Piçarrão sentido da sede do lado direito em mata seca, 28-X-2011, fr., M.M. Dantas 20 (UFG); idem, ibidem, M.M. Dantas 21 (UFG).

Material adicional examinado: BRASIL. GoIÁs: Abadiânia, entre Anápolis e o povoado de Planalmira na borda da estrada, 18-XI-2011, fl., M.M. Dantas 35 (UFG); Corumbá de Goiás, lado esquerdo do trevo de Corumbá em direção a Pirenópolis, 18-XI-2011, fl., M.M. Dantas 36 (UFG); Leopoldo de Bulhões, $\mathrm{km} 47$ próximo a Granja Josedith na margem direita da rodovia sentido Goiânia-Leopoldo de Bulhões, 8-XII-2011, fl., fr., M.M. Dantas 67, 68 (UFG).
Táxon encontrado nas regiões Centro-Oeste (DF, GO, MT e MS), Nordeste (BA e MA) Norte (PA e TO) e Sudeste (MG e SP) ocorrendo geralmente em ambientes perturbados no Cerrado, pastagens, clareira de floresta estacional e também em mata de galeria (Souza \& Bortoluzzi 2012).

De acordo com Irwin \& Barneby (1982) Senna silvestris inclui duas subespécies (silvestris e bifaria) diferenciadas principalmente pela presença ou ausência de tricomas nos folíolos, área de distribuição e número e arranjo dos óvulos no ovário. Estes mesmos autores reconheceram algumas variedades, como por exemplo, as variedades bifaria, unifaria e velutina para a subespécie bifaria e as variedades guaranitica, sapindifolia e silvestris para a subespécie silvestris. O táxon aqui encontrado corresponde a S. silvestris subsp. bifaria e diferencia-se dos demais reconhecidos por Irwin \& Barneby (1982) pelos frutos com 1,8-3 cm de largura, ovário com 40-58 óvulos, sementes bisseriadas, além de ramos curtamente vilosos, hábito arborescente e com distribuição principal na porção central do país.

Neste estudo $S$. silvestris subsp. bifaria foi coletada em borda de floresta estacional próximo a córregos e pode ser reconhecida entre as demais espécies aqui tratadas pelas folhas com 4 a 8 pares de folíolos lanceolados a oval-lanceolados, panículas com eixos secundários corimbiformes e frutos compressos vináceos com margem esverdeada e nervuras destacadas. Floresce e frutifica de maio a dezembro.

\section{Agradecimentos}

Agradecemos ao Conselho Nacional de Desenvolvimento Científico e Tecnológico (CNPq) pela Bolsa de Iniciação Científica do primeiro Autor (processo $n^{\circ} 140609 / 2006-7$ ), ao Prof. Dr. Aristônio Magalhães Teles pelo apoio logístico por meio do projeto "Estudo Florístico do Parque Estadual da Serra Dourada" (CNPq 477620-2009/4) e a Cristiano Gualberto Santos pelas ilustrações das espécies.

\section{Literatura citada}

Angely, J. 1965. Flora analítica do Paraná. Universidade de São Paulo, São Paulo.

Alves, F.M. \& Sartori, A.L.B. 2009. Caesalpinioideae (Leguminosae) de um remanescente de Chaco em Porto Murtinho, Mato Grosso do Sul, Brasil. Rodriguésia 60: 531-550. 
Bortoluzzi, R.L.C. 2004. A subfamília Caesalpinioideae (Leguminosae) no estado de Santa Catarina, Brasil, Tese de Doutorado, Universidade Federal do Rio Grande do Sul, Porto Alegre.

Cochrane, T.T., Sanchez, L.G., Azevedo, LG., Porras, J.A. \& Garver, C.L. 1985. Land in Tropical America.v. 3. CIAT/EMBRAPA- CPAC, Cali, pp. 1-147.

Fernandes, A. 1962. Leguminosas do município de Fortaleza - Subfamília Caesalpinioideae. Boletim da Sociedade Cearense de Agronomia 3: 25-32.

Lima, J.E.G. 1999. Os gêneros Cassia L. e Senna Mill. (Leguminosae: Caesalpinioideae: Cassieae) no estado de Pernambuco-Brasil. Dissertação de Mestrado, Universidade Federal Rural de Pernambuco, Recife.

Irwin, H.S. \& Barneby, R.C. 1982. The American Cassiinae: A synoptical revision of Leguminosae - Tribe Cassieae subtribe Cassiinae in the New World. Memoirs of the New York Botanical Garden 35: 1-918.

Köppen, W. 1948. Climatologia: con un estudio de los climas de la tierra. Fondo de Cultura Econômica, México.

Lewis, G.P. 1987. Legumes of Bahia. Royal Botanic Gardens, Kew.

Lewis, G.P. 2005. Tribe Cassieae. In: G.P. Lewis, B. Scrhire, B. Mackinder \& M. Lock (eds.). Legumes of the World. Royal Botanic Gardens, Kew, pp. 111-125.

Lewis, G.P. \& Owen, P.E. 1989. Legumes of the Ilha de Maracá. Royal Botanic Gardens, Kew.
Marazzi, B., Endress, P.K., Queiroz, L.P. \& Conti, E. 2006. Phylogenetic relationships winthin Senna (Leguminosae, Cassinae) based on three chloroplast regions: patterns in the evolution of floral symmetry and extrafloral nectaries. American Journal of Botany 93: 288-303.

Mori, S.A., Silva, L.A.M., Lisboa, G. \& Coradin, L. 1989. Manual de manejo do herbário fanerogâmico. Centro de Pesquisa do Cacau, Ilhéus.

Queiroz, L.P. 2009. Leguminosas da caatinga. Universidade Estadual de Feira de Santana, Feira de Santana.

Rizzo, J.A. 1970. Contribuição ao conhecimento da Flora de Goiás, Área na Serra Dourada. Tese de Livredocência, Universidade Federal de Goiás, Goiânia.

Rodrigues, R.S., Flores, A.S., Miotto, S.T.S \& Baptista, L.R.M. 2005. O gênero Senna (Leguminosae, Caesalpinioideae) no Rio Grande do Sul, Brasil. Acta Botanica Brasilica 19: 1-16.

Silva, M.J \& Tozzi, A.M.G.A. 2010. Leguminosaesubfamília Caesalpinioideae. In: M.M.R.F. Melo, F. Barros, S.A.C. Chiea, M. Kirizawa, S.L. JungMendaçolli \& M.G.M. Wanderley (eds.). Flora Fanerogâmica da Ilha do Cardoso, v.15, Instituto de Botânica, Brasil. pp. 17-41.

Souza, V.C. \& Bortoluzzi, R.L.C. 2012. Senna. In: R.C. Forzza, A. Costa, B.M.T. Walter, J.R. Pirani, M.P. Morim, L.P. Queiroz, G. Martinelli, A.L. Peixoto, M.A.N. Coelho, J.F.A. Baumgratz, J.R. Stehmann, L.G. Lohmann, M. Hopkins. Lista de Espécies da Flora do Brasil. Jardim Botânico do Rio de Janeiro, Rio de Janeiro. http://floradobrasil.jbrj.gov.br/2012/FB023149 (acesso em 10.08.2012). 
